\title{
A MEDIAÇÃO COMO INSTRUMENTO DE DEMOCRATIZAÇÃO DO ACESSO À JUSTIÇA E EMANCIPAÇÃO DAS MINORIAS
}

\author{
Teodolina Batista da Silva Cândido Vitório ${ }^{1}$ \\ Alexsandrina Ramos de Carvalho Souza ${ }^{2}$
}

\section{RESUMO:}

A dialética em torno da mediação e conciliação como instrumentos de democratização do acesso à justiça e emancipação das minorias é a força motriz deste ensaio. A expressiva judicialização dos conflitos sociais pós $\mathrm{CRFB} / 88$ é um dos plúrimos fatores que tem determinado o congestionamento do Judiciário. Destarte, objetiva-se investigar se estes novos meios estão de fato sendo eficazes na promoção da democracia, garantindo o acesso à justiça. Conclui-se que existe sim uma sintonia entre sociedade e Estado para a consecução deste ideal que vem lentamente se consolidando por meio de políticas de fomento à solução pacífica das controvérsias.

Palavras-Chave: Mediação; conciliação, acesso à justiça; minorias; direitos humanos.

\section{THE MEDIATION AS INSTRUMENT OF DEMOCRATIZATION OF ACCESS TO JUSTICE AND MINORITIES EMANCIPATION}

\begin{abstract}
:
The dialectic around mediation and conciliation as democratization instruments of access to justice and the emancipation of minorities is the driving force of this essay. The expressive judicialization of conflicts after the 1988 Constitution is one of the factors that has determined the congestion of the Judiciary. Thus, this paper aims to investigate if these methods are being capable of promoting democracy and the access to justice. Finally, it concludes that there is a fruitful union of forces between society and the State to achieve this ideal that has been slowly materializing through policies to foster peaceful settlement of disputes.
\end{abstract}

Keywords: Mediation; conciliation; access to justice; minorities; human rights.

\section{INTRODUÇÃO}

\footnotetext{
${ }^{1}$ Pós-Doutorado em Direito pela Università degli Studi di Messina, Itália. Doutorado em Direito pela Pontifícia Universidade Católica de Minas Gerais - PUC/MG. Mestrado em Direito pela Universidade Gama Filho UGF/RJ. Professora do programa de pós-graduação e do curso de graduação em Direito e membro do grupo de pesquisa direitos humanos e acesso à justiça e mediação da Faculdade de Direito do Vale do Rio Doce (Fadivale). Advogada. E-mail: linaadv@terra.com.br

${ }^{2}$ Doutoranda em Ciências da Comunicação pela Unisinos/RS. Mestrado em Direito Público pela Universidade FUMEC-BH. Professora do programa de pós graduação e do curso de graduação em Direito e membro do grupo de pesquisa direitos humanos e acesso a justiça e mediação da Faculdade de Direito do Vale do Rio Doce (Fadivale). Advogada. E-mail: alexsandrina@hotmail.com
} 
A dialética em torno da mediação e a conciliação como instrumentos de promoção dos direitos humanos, de democratização do acesso à justiça e emancipação das minorias é a força motriz do presente ensaio, abordagem essa de imensurável relevância, que tem guardado a mais plena sintonia com os desafios da pós-modernidade.

A expressiva onda de judicialização dos conflitos sociais deflagrada pós Constituição-Cidadã de 1988 é um dos plúrimos fatores que tem determinado o congestionamento do Poder Judiciário, o qual não consegue oferecer em tempo hábil uma resposta satisfatória às demandas submetidas a sua apreciação.

Dados divulgados pelo Conselho Nacional de Justiça (CNJ), ano-base de 2017, demonstram que a taxa de congestionamento processual no período de 2009 a 2017, é expressivamente alta, 73,7\% ( $\left.1^{\circ} \mathrm{grau}\right)$ e 53,9\% ( $\left.2^{\circ} \mathrm{grau}\right)$. Em Minas Gerais, o índice foi de $70 \%$ ( $1^{\circ}$ grau $)$ e $57 \%$ ( $2^{\circ}$ grau). Quanto maior o índice, maior a dificuldade do tribunal em lidar com seu acervo de processos (CNJ, 2019a). Mais latente também é a morosidade processual, selo da ineficiência estatal que viola o meta princípio da dignidade da pessoa humana, já tendo no passado assim proclamado a respeito o imortal Rui Barbosa: "Justiça tardia é injustiça qualificada e manifesta” (BARBOSA, 2014, p. 53).

Neste contexto exsurgem a mediação e a conciliação, além de outros meios de pacificação de controvérsias. Estes novos modelos, secundariamente, desafogam o Judiciário, bem como, principalmente, restabelecem e preservam os vínculos sociais e afetivos antes interrompidos entre os indivíduos.

Destarte, este trabalho objetiva investigar se a mediação e a conciliação estão de fato se revelando potencialmente capazes de promover a democracia, instrumentalizando as minorias com os seus direitos e garantias constitucionais.

Atinente a metodologia, adotou-se a vertente jurídico-sociológica com abordagem dedutiva, valendo-se da pesquisa bibliográfica e documental e o tipo pesquisa-ação (GUSTIN e DIAS 2015, p. 22-23, p. 88).

A estruturação deste artigo deu-se a partir do alinhamento dos seguintes capítulos: uma abordagem acerca do acesso à Justiça, no capítulo segundo; o capítulo terceiro cuidou da Política Judiciária Nacional de tratamento adequado de conflitos; no quarto apresentou a Justiça em números; o quinto teceu-se relevantes argumentos acerca da mediação e da conciliação como vetores de democracia, cidadania e direitos humanos no processo de emancipação das minorias. Prossegue no quinto elencando os principais desafios da mediação 
e da conciliação, revelando as estratégias Fadivaleanas de enfrentamento desse preocupante cenário. Por derradeiro no capítulo seis apresentam as considerações finais.

\section{O ACESSO À JUSTIÇA}

Desde os tempos mais remotos as civilizações insistem na consagração do direito de acesso a justiça como um reconhecido talismã da humanidade. Hamurábi, em seu venerando Código (1.792 a.C), assim promulgava:

\footnotetext{
Em minha sabedoria eu os refreio para que o forte não oprima o fraco e para que seja feita justiça à viúva e ao órfão. Que cada homem oprimido compareça diante de mim, como rei que sou da justiça. Deixai-o atentar nas minhas ponderadas palavras. E possa o meu monumento iluminá-lo quanto à causa que traz, e possa ele compreender o seu caso (CARNEIRO, 2000, p. 3).
}

O Código de Manu (1.000 a.C), na Índia, em seuart. $8^{\circ}$ e a Lei das XII Tábuas (462 a.C), na Tábua Primeira, em Roma, consagraram o acesso a justiça traduzindo um retrato social de recorrentes lutas por bandeiras que se manteriam para sempre erguidas no mastro das gerações (dimensões) de direitos sob a insígnia da igualdade, liberdade, fraternidade e dignidade (CÓDIGO DE MANU, 2019; LEI DAS XII TÁBUAS, 2019).

Na Grécia, notória era a proeminência de Atenas, a Cidade Antiga, pioneira nas garantias democráticas, ao assegurar aos cidadãos a prevalência do direito a um julgamento, exceto, ensina Bedin (2013, p. 93), as mulheres, escravos e a estrangeiros, por não serem à época indivíduos legitimados.

Nesse traço histórico merecem relevo as contribuições de Sócrates (469-399 a.C), de seu discípulo Platão (427-347 a.C) e Aristóteles (384 a.C - 322 a.C) (ARISTÓTELES, 1984), que estabeleceram os fundamentos do direito germano-romano na ideia de justiça inspirada a partir das relações sociais regidas pela ética, equidade e pela moral. Sem esses sublimes valores torna-se inalcançável a dialética imprescindível à construção de um terceiro caminho entre as partes processuais pautado pela alteridade, amor e tolerância, amálgama da cultura de paz sonhada por mediadores, conciliadores, consteladores e demais atores dos meios adequados de solução das controvérsias.

Na Idade Média a religião tornou-se a voz do direito, sendo então a sentença do soberano um reconhecido direito das pessoas, emanada dos deuses, absoluta e inquestionável. 
A Declaração Universal de Direitos Humanos (Paris, 1948), em seu art. 10 assevera que toda pessoa tem direito, em plena igualdade, a julgamento público, imparcial e independente (ONU, 2019).

A Constituição Federal, em seu artigo 5, XXXV, determina que: "a lei não excluirá da apreciação do Poder Judiciário lesão ou ameaça a direito" (BRASIL, 2019a, p. 3). A questão que se coloca é a seguinte: o acesso à justiça, constitucionalmente garantido, tem assegurado a prestação jurisdicional efetiva e eficaz?

O tema acesso à justiça tem sido uma preocupação mundial, desde os anos da década de 1970. Cappelletti refere-se a direito social básico, devendo ser garantido via prestação positiva do Estado, vejamos:

\footnotetext{
Entre esses direitos garantidos nas modernas constituições estão os direitos ao trabalho, à saúde, à segurança material e à educação. Tornou-se lugar comum observar que a atuação positiva do Estado, necessária para assegurar o gozo de todos esses direitos sociais básicos. Não é surpreendente, portanto, que o direito ao acesso efetivo à justiça tenha ganhado particular atenção[...] (CAPPELLETTI e GARTH, 1988, p. 11, grifo nosso).
}

Prefalado autor conceitua acesso à justiça sob dois pontos de vista, quais sejam: "a possibilidade de as pessoas reivindicarem direito e/ou resolverem conflitos no Judiciário" e também "a possibilidade de terem acesso a resultados que sejam individual e socialmente justos". (FULLIN, 2013, p. 219).

Cappelletti e Garth (1988) apontam várias barreiras ao acesso à justiça, como aquelas de natureza econômica, cultural e burocrática. Três são as ondas para superá-las: a primeira aponta para o enfrentamento das barreiras econômicas a partir da implantação das defensorias públicas. A segunda é voltada para a desburocratização dos procedimentos. Já a terceira trata dos meios alternativos de administração de conflitos, como por exemplo, conciliação e mediação.

Neste cenário, insere-se a Resolução 125 de 2010 do CNJ, por meio da qual se instituiu a Política Judiciária Nacional de Tratamento Adequado dos Conflitos de Interesses no âmbito do Poder Judiciário, passando-se a seguir a sua detida leitura.

\section{POLÍTICA JUDICIÁRIA NACIONAL DE TRATAMENTO ADEQUADO DE CONFLITOS}


A formulação e implementação desta política é complexa e compreende várias etapas que se desenvolvem em conjunturas específicas. A dinâmica desse processo é marcada pela interação política de diversos atores sociais. A participação desses atores ocorre por via direta (participação em assembleias, audiências públicas) ou indireta, por meio de representantes, em várias instâncias de negociação.

Formalmente pode-se estabelecer as seguintes etapas do processo de institucionalização de política pública que, contudo, não acontece de forma linear na prática, pois uma etapa não evolui, necessariamente, para a outra, conforme preleciona Pedone (1986 apud SILVA e PEDONE, 1988, p. 206).

Considerando a política em tela, pode-se afirmar que a escolha de instrumentos legais e institucionais decorre, em grande parte, da concepção que os atores têm da questão como problema social, da determinação de concepções e papéis com relação ao acesso à justiça, das demandas societais e da capacidade de resposta do poder público, tendo em vista a articulação de outras agendas governamentais e a limitação dos recursos.

A escolha, neste caso, é definida por meio de disputas políticas, em arenas específicas, envolvendo os principais atores político-institucionais e os grupos de interesse. Um dos problemas que surgem no processo de formulação das políticas governamentais refere-se à participação diferenciada dos diversos atores no jogo político.

Em última instância, esta participação é definida em função do acesso a recursos econômicos, político-institucionais, incentivos e informações por parte dos atores, dentre outros. Estes fatores definirão também, via de regra, a apropriação dos benefícios produzidos pelas políticas.

Entende-se que acesso a resultado justo desloca a ênfase da normatividade para o campo da emancipação, como materialização daquilo que já foi estabelecido formalmente em lei. Ou seja, a eficácia do acesso à justiça depende da concretização deste direito fundamental. Neste caso, deve-se questionar a possibilidade ou não de adequação entre a norma e suas finalidades sociais, isto é, verificar se a norma alcança seus objetivos. Eficaz, portanto, é a norma que tem força para promover os efeitos sociais que deram origem a sua produção em consonância com a realidade social na qual se aplica (CAVALIERI FILHO, 2003).

Por oportuno, saliente-se que merece especial relevo dentre tais condicionantes, a imprescindibilidade do conflito ser tratado pelo Poder Judiciário “em tempo hábil”. Para a garantia do acesso à justiça é necessário que o direito seja célere, efetivo, gerando um 
resultado prático e justo. Afinal, aí reside o centro gravitacional do princípio constitucional da razoável duração do processo (art. 5. ${ }^{\circ}$, LXXVIII da CFRB/88).

Neste sentido, vários são os preceitos legais voltados para a solução adequada de conflitos: a Constituição Federal de 1988, Código de Processo Civil (CPC) de 2015, a Lei de Mediação $n^{\circ} 13.140 / 2015$, assim como a Lei $n^{\circ} 9.307 / 96$ (Arbitragem) alterada pela Lei de $n^{\circ}$ 13.129/15. Impende ressaltar a finalidade da Resolução 125/2010 do CNJ que não é outra senão promover a cultura da pacificação social, em detrimento da cultura do litígio. Isto se torna possível a partir da concretização desse direito ao acesso à justiça, com resposta tempestiva.

O CPC/2015 se insere na tendência dos movimentos globais de desburocratização da justiça, colocando na centralidade a via conciliatória. Foi cortejado pela Lei ${ }^{\circ} 13.140 / 2015$ que abrange os direitos disponíveis e os indisponíveis que admitam transação, adotando a mediação, no âmbito público e privado como instrumento de acesso à justiça.

É justo nesse cenário que tornam-se inquietantes os dados que serão analisados na seção 4, que revelam um impactante colapso do sistema, retratado numa morosidade processual sem proporção, comprometendo severamente o direito fundamental de acesso à justiça, cujo resgate tem sido enfrentado como principal desafio da mediação e da conciliação.

\section{A JUSTIÇA EM NÚMEROS}

A expressiva onda de judicialização dos conflitos sociais deflagrada pós Constituição-Cidadã de 1988 tem determinado o congestionamento do Poder Judiciário, que não consegue oferecer uma resposta satisfatória às demandas submetidas a sua apreciação. Dados divulgados pelo CNJ, ano-base de 2017, demonstram que a taxa de congestionamento ${ }^{3}$ do Poder Judiciário, no período de 2009 a 2017, é expressivamente alta, 73,7\% (em $1^{\circ} \mathrm{Grau}$ ) e $53,9 \%\left(2^{\circ} \mathrm{Grau}\right)$. Em Minas Gerais, o índice foi de $70 \%$ ( $\left.1^{\circ} \mathrm{Grau}\right)$ e $57 \%$ ( $\left.2^{\circ} \mathrm{Grau}\right)$. Quanto maior o índice, maior a dificuldade do tribunal em lidar com seu acervo que já contabilizou em 2015 o índice de mais de 100.000.000 milhões de feitos em tramitação (CNJ, 2019a).

\footnotetext{
${ }^{3}$ Taxa de congestionamento: mede o percentual de casos que permaneceram pendentes de solução ao final do ano-base, em relação ao que tramitou (soma dos pendentes e dos baixados).
} 
Em 2017, o Poder Judiciário finalizou o ano com 80,1 milhões de processos em tramitação, aguardando alguma solução definitiva. Em média, a cada grupo de 100.000 habitantes, 12.519 ajuizaram uma ação judicial e, em Minas Gerais este número foi de 7.471.

Merece destaque ainda, o elevado custo do Poder Judiciário. Em 2017, as despesas totais somaram R $\$ 90,8$ bilhões - 1,4\% do Produto Interno Bruto (PIB) nacional -, sendo que os gastos com recursos humanos representam 90\% da despesa total. Cortez (2019) relata, com base da pesquisa de Samuel Pessôa da Fundação Getúlio Vargas (FGV), que o Brasil gasta quase $2 \%$ do PIB com o judiciário; quatro vezes a média dos países que fazem parte da Organização para a Cooperação e Desenvolvimento Econômico (OCDE),

Nesse contexto, a Resolução 125/10 do CNJ que instituiu a Política Judiciária Nacional de tratamento dos conflitos e a Resolução, representa um avanço, quando em seu artigo $8^{\circ}$, determinou que os Tribunais de Justiça criassem os Centros Judiciários de Solução de Conflitos e Cidadania (CEJUSCS).

Em 2017, o Índice de conciliação (IC) em toda a Justiça foi de 12,10\% (Tabela 1) de processos resolvidos por meio de acordos (mediação ou conciliação), constituindo 3,7 milhões, em um universo de 31 milhões de sentenças.

Tabela 1 - Índice de conciliação (IC) e CEJUCs - Brasil e Minas Gerais.

\begin{tabular}{c|c|c|c|c}
\hline & $\begin{array}{c}\text { IC } \\
\text { PODER } \\
\text { JUDICIÁRIO } \\
\text { BnASIL }\end{array}$ & IC & $\begin{array}{c}\text { JUSTIÇA } \\
\text { ESTADUAL - } \\
\text { CEJUSCS/BRASIL }\end{array}$ & $\begin{array}{c}\text { CEJUSC } \\
\mathrm{S}\end{array}$ \\
\hline 2015 & $11,10 \%$ & $13,70 \%$ & 654 & $\mathrm{MG}$ \\
2016 & $11,90 \%$ & $15,03 \%$ & 808 & 93 \\
2017 & $12,10 \%$ & $18,80 \%$ & 982 & 123 \\
\hline
\end{tabular}

Fonte: CNJ, 2019a. Justiça em números 2018.

Atualmente, em Minas Gerais, há 148 Centros Judiciários. A Tabela 1 mostra o IC do TJMG, o qual obteve o maior índice entre os tribunais de grande porte (São Paulo, Minas Gerais, Rio Grande do Sul, Paraná e Rio de Janeiro), 18,80\% e 123 CEJUSCS na Justiça Estadual, maior que 2016 com IC de 15,3\% e 93 CEJUSCS, sinalizando uma justiça mais próxima do cidadão.

Em Governador Valadares (GV-MG), o CEJUSC foi o oitavo a ser instalado (21/03/2014), integrando os setores de cidadania, pré-processual e processual. 


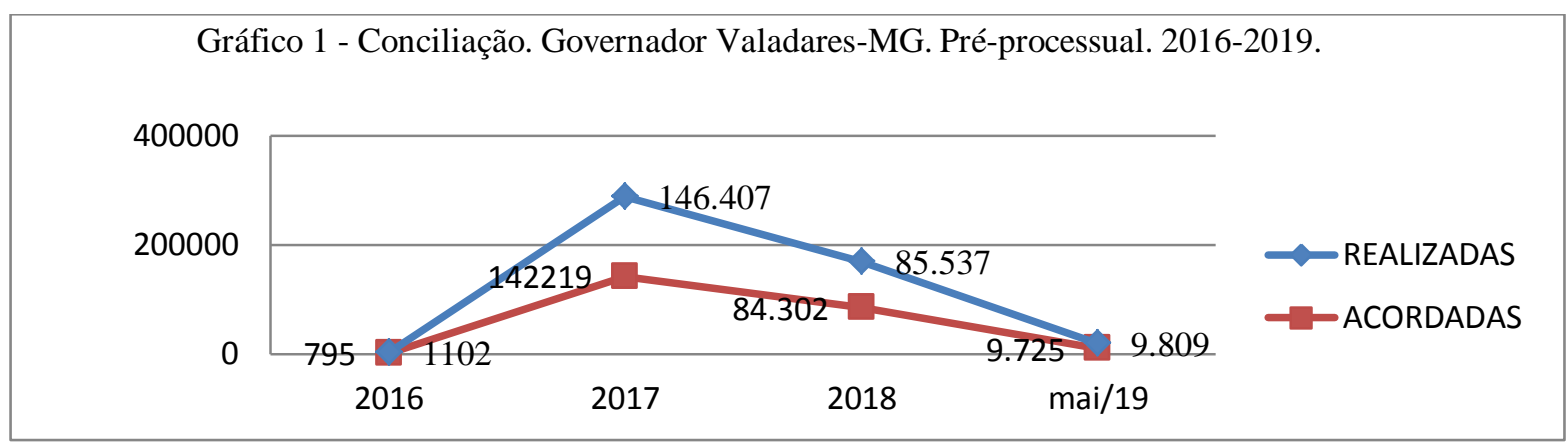

Fonte: Minas Gerais, 2019.

Os Gráficos 1 e 2 apresentam os dados da Conciliação pré-processual e processual em GV-MG. A pré-processual apresenta números em queda e a processual aumento. Destacando que em 2017, o CEJUSC homologou, somente entre a Fundação Renova e os cidadãos valadarenses, um total de 25.550 acordos pré-processuais, em decorrência da interrupção de água na região, causado pelo rompimento da barragem de Fundão em Mariana -MG.

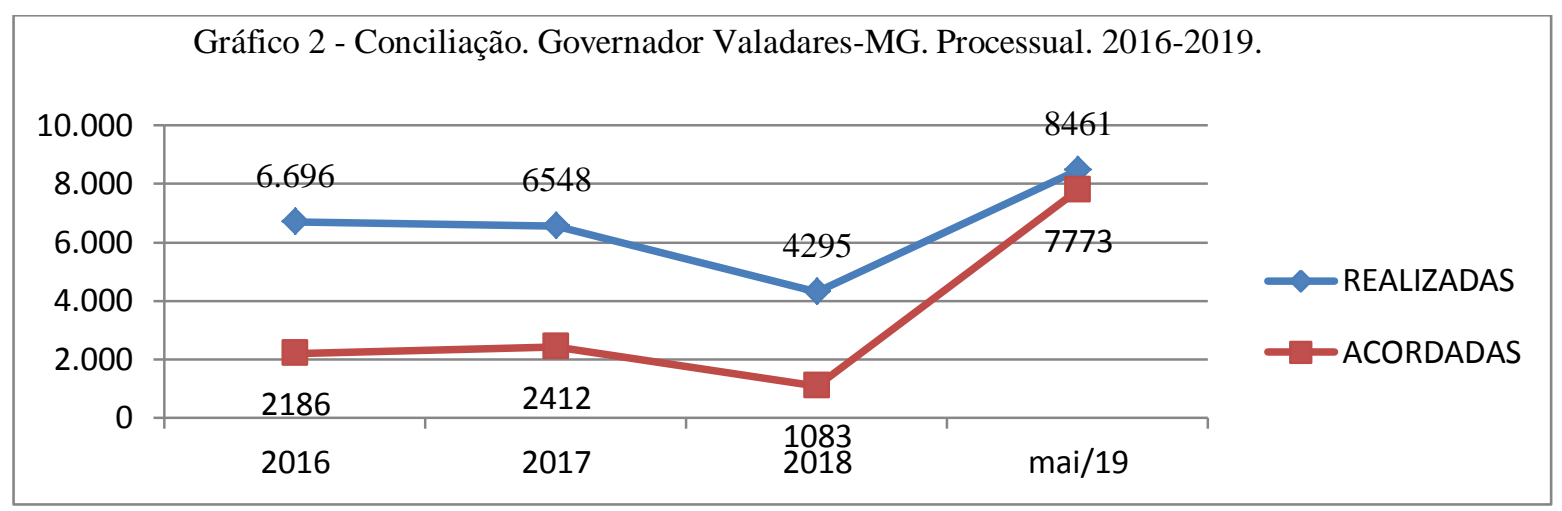

Fonte: Minas Gerais, 2019.

No ano de 2018, Minas Gerais apresentou um número de 2.040 acordos na mediação processual e 2.580 na pré-processual, conforme o TJMG. Representam 4.620 autocomposições dignas de ser celebradas, uma vez que pressupõe a emancipação das minorias pelo exercício da cidadania e de seus direitos democráticos.

5 A MEDIAÇÃO E A CONCILIAÇÃO COMO VETORES DE DEMOCRACIA, CIDADANIA E DIREITOS HUMANOS NO PROCESSO DE EMANCIPAÇÃO DAS MINORIAS 
Atinente à democracia, denota-se que hodiernamente sua efetividade encontra-se não mais absolutamente centrada na figura do Estado, mas sim na maior participação política dos cidadãos. Trata-se de uma concepção baseada numa racionalidade comunicativa, permitindo um envolvimento do Estado com as pessoas na busca de um entendimento, conforme a Teoria da Ação Comunicativa de Jürgen Habermas (HABERMAS, 1999). Para o autor, além de uma razão instrumental, haveria uma razão comunicativa, fundada na linguagem, que buscava a sua validade no consenso entre os diversos membros de uma comunidade, pelo diálogo. A razão comunicativa se encontra no "mundo da vida", formada por elementos da cultura, da sociedade e personalidade.

De acordo com Habermas (1999), as sociedades contemporâneas, pós-convencionais e complexas, possuem condições precárias de integração social, com arranjos que potencializam os conflitos, que prejudicam a formação de unidades axiológicas e impedem a emancipação do homem. Diante deste quadro, os indivíduos direcionam suas ações por critérios de racionalidade meramente instrumentais, em busca de interesses próprios ou adotando decisões arbitrárias. Assim, o indivíduo atua sobre o outro e não com o outro, agindo racionalmente com direção a "fins" meramente estratégicos.

No entanto, Cittadino (2004) esclarece que a ação comunicativa altera a relação entre as pessoas, transformando o subjetivo em intersubjetivo, o que possibilita uma maior compreensão da necessidade individual, da coletiva e do bem-estar social e, assim, contribuindo com a organização social, a elaboração e a validação de normas.

Para Habermas (1999), os indivíduos, através da linguagem e da ação, podem estabelecer práticas argumentativas compartilhando um contexto comum do mundo vivido, assumindo as suas responsabilidades como membros da sociedade.

Por intermédio desse entendimento busca-se a concretização da cidadania e a participação social ativa, que tem no agir comunicativo, o principal meio para se chegar a um consenso, formado por uma consciência moral e respeito ao próximo.

E neste contexto aparece a mediação como meio de pacificação social que auxilia os indivíduos envolvidos a buscar resolver e prevenir os conflitos de maneira pacífica e inclusiva, através do diálogo, com respeito ao outro, com ativa participação e responsabilidade dos interessados pela resolução do conflito, observando-se o devido equilíbrio entre as partes. 
Na medida que a mediação estimula a participação ativa dos cidadãos na resolução do seu conflito, "considerando-os capazes de encontrar, por si mesmos, as soluções mais adequadas para o conflito, contribui para essa nova visão de cidadania, na qual o indivíduo se torna protagonista e responsável por suas escolhas e seu destino" (MOREIRA, 2007, p. 89).

Ao privilegiar e facilitar a atuação dos indivíduos no processo de construção de alternativas viáveis para os seus conflitos, a mediação também desperta neles o sentimento de que são capazes de solucionar não só seus problemas pessoais, mas também de atuar para a melhoria da vida em comunidade. O indivíduo incluído e valorizado, tem uma maior consciência de seus direitos e de sua responsabilidade social.

E neste contexto se sobressai a denominada mediação comunitária que vem desenvolvendo importante papel, enquanto procedimento não adversarial de resolução de conflitos, de natureza gratuita, em comunidades periféricas e carentes. Os mediadores comunitários desempenham uma atividade agregadora, despertando os moradores locais para a importância do coletivo.

Dentre tais inquietantes e prementes desafios, que notoriamente atrofiam ainda mais os trôpegos passos do Estado na prestação jurisdicional que inequivocamente é determinante para a promoção do meta princípio constitucional da dignidade da pessoa humana, sublinhamse:

a) A postura reticente do Poder Judiciário e seus agentes frente aos procedimentos de mediação e conciliação

Aludida postura influencia negativamente advogados(as) e jurisdicionados(as) que, via de consequência, em alguma medida, adotam um nefasto sentimento de desprezo, desconfiança e insegurança nas respectivas seções/audiências. Alguns destes, muitas vezes nem mesmo comparecem, ainda que tenham sido intimados, até mesmo preferindo a condenação em multa de $2 \%$ (dois por cento) prevista no art. $334, \S 8^{\circ}$ do CPC, mantendo-se céticos e resistentes a qualquer diálogo e/ou autocomposição.

A Mediação e a Conciliação não mitigam a toga da magistratura, nem estabelece competição ou concorrência com seus títulos ou status.

Muito ao reverso, é um instrumento técnico altamente poderoso colocado ao seu dispor que efetivamente permite a solução pacífica das controvérsias, (compromisso esse celebrado no preâmbulo da Constituição Federal), rompendo com a cultura do litígio e com o 
árido cumprimento de uma gélida e interminável pauta processual objeto de uma rotina exaustiva e na maioria das vezes ineficaz.

Nesse diapasão, merece relevo a lição de Lima (2017, p. 265, grifo nosso), quando indaga acerca das razões desta resistência, conclamando o mundo jurídico a uma postura mais humana, regida pela flexibilidade, amor e compaixão na busca de soluções para os conflitos analisados, tal como adiante delineado ipsis litteris:

\begin{abstract}
Você acha que a mediação é uma nova visão de justiça, que está chegando neste momento? É uma justiça nova? Diferente? Observamos vários países trabalhando com a mediação, como EUA e Canadá, desde 1970, e alguns, como o Brasil, apresentando muita resistência à sua adoção.

Não há justiça nova ou velha. Justiça é justiça em qualquer tempo. A Mediação não contraria o poder judiciário. $\hat{\mathbf{E}}$ um procedimento, digamos mais humanizado no terreno angustioso dos conflitos no mundo.

É justo indagarmos a razão dessa resistência, uma vez que na mediação os advogados e Juízes terão condições de intervir com muita humanidade e receber o bônus da alegria, da ventura junto ao salário que por direito recebem. No procedimento convencional alguns advogados litigam durante meses ou anos, estendendo penso que sem pretender, a rede dos conflitos no tempo, conflitos esses que amarguram os corações, interferem nas relações humanas, produzindo cansaço, levando muitas vezes à ruptura de laços afetivos por tempo indeterminado, adiando a solução desejável que é o entendimento entre os mediados, o que, no procedimento da mediação é o objetivo principal. Entendemos que o tempo do litigio é o salário garantido ao profissional que opera. E na atualidade, sabemos que os profissionais da magistratura são promovidos por número de processos baixados. Será justo sermos promovidos, despreocupados das dores geradas por sentenças muitas vezes cheias de equívocos? Não podemos nos esquecer de que o Juiz é o médium da lei.
\end{abstract}

Salta aos olhos na obra supracitada a acentuada angústia daquela jurista com a insensibilidade latente em alguns julgados convertidos em meros números, que por sua vez são transformados em visíveis degraus calculados com vistas nem sempre à emancipação dos cidadãos por uma justiça hercúlea e libertadora, mas com vistas sim à autopromoção do(a) próprio(a) julgador(a|). Idealizou a Mediação Construtivista em que o mediador efetua intervenções pontuais contribuindo com os interessados no esvaziamento da espiral de conflitos por meio da Técnica Tocando nas Estrelas, de autoria da psicóloga e mediadora Berenice Neide Brandão. Nesse movimento de paz promove-se a "construção de um acordo sustentável, digno, sólido, duradouro, adequado à realidade dos envolvidos no conflito e favorável a todos os protagonistas.” ( BRANDÃO apud LIMA, 2017, p. 9). 
Lima (2017, p. 266) preconiza ainda em sua obra que "Quem trabalha com humanidade, pensa primeiro no bem estar geral, pensa em apagar o incêndio provocado pela dor, pela revolta, pelo abandono, pela ignorância [...]" e prossegue de forma magistral:

\footnotetext{
Penso que a Mediação precisa ocupar seu lugar na sociedade, para que, no desempenho de seu legítimo papel, possa ajudar na construção da harmonia na vida dos seres, dos lares, das nações...

A Magistratura no Brasil, sem explicação, caminha a passos lentos, mostra-se inibida para interferir com brilhantismo na vida do povo.

É lícito afirmar que existem almas atentas, honradas, predispostas a somar esforços para um mundo melhor e que constituem alicerce seguro para quantos queiram operar a lei com brilhantismo.

Sabemos igualmente que falta consciência a um número expressivo ...

Quem trabalha com humanidade, pensa primeiro no bem-estar geral, pensa em apagar o incêndio provocado pela dor, pela revolta, pelo abandono, pela ignorância ...

Entendemos que o mediador tem como característica de base, a compaixão, a flexibilidade, o amor [...].
}

Dessarte, é injustificável a resistência apresentada por alguns membros do Judiciário à mediação e a conciliação, uma vez que esses métodos são mananciais a serviço dos cidadãos que anseiam por libertar-se dos dramas que lhes oprimem e assaltam-lhes a dignidade, a honra e a paz.

b) O desprezo da lide sociológica e a maximização da lide processual

Como é cediço, uma das escolas clássicas que inspiram as múltiplas formas de compreensão e realização eficaz da mediação é a "Transformativa". Trata-se de modelo idealizado por Robert A. Barush Bush, expert da área de Negociação e Joseph F. Folger, pensador da Comunicação, que ensinam que o objetivo da mediação não está situado prioritariamente na realização do acordo; seu mais sublime ideal consiste em identificar e elaborar um ponderado diálogo sobre os reais interesses e necessidades das pessoas envolvidas no conflito.

Luís Albert Warat, pesquisador argentino, jurista, filósofo, psicanalista e amante da literatura, por sua vez, criou a Escola Waratiana tecida sob o manto do amor e da compaixão, revelando técnicas que esvaziam a carga de energia negativa das pessoas envolvidas em um litígio para que então, livres desses fardos, consigam forças e motivações suficientes para que eles próprios administrem de forma pacífica e criativa os seus dissensos. Empodera-os para serem senhores de suas próprias respostas buscadas no litígio, elaboradas pacificamente. Dessume-se portanto, que seu desiderato maior também não reside no acordo mas sim "que a 
mediação seja vista sob a ótica da alteridade, do amor, da compaixão e do prazer" (ROCHA, LOIS e MELEU, 2019).

Essa perspectiva essencialmente humanizada e espiritualizada da mediação é recorrente em Jean-François Six, Presidente do Centre National de la Mediaton, Filósofo, Escritor e Membro Fundador do Haut Conseil de la Mediaton, Membro da Comission Nationale Consultative des Droits de L`Homme:

No outro extremo do mundo da ciência e da verificação, encontra-se ainda a mediação. Mediadores invisíveis invadiram nossa época há alguns anos: os anjos. Nesse mundo que seciona e separa, o nosso, eles são inventados para incitar a comunicação e a união, já que estabelecem passarelas contínuas entre o céu e a terra, o espiritual e o material (SIX, 2001, p. 17).

Nesse mesmo diapasão, exsurge a prefalada Escola Construtivista de autoria da professora Fernanda Lima, Presidenta da Fundação Nacional de Mediação de Conflitos, "fomenta o diálogo, a reaproximação das partes envolvida, a criação ou reconstrução do afeto, gerando a possibilidade de uma comunicação eficaz, potencialmente capaz de construir novos caminhos pautados no respeito e na paz. "O conflito é transformado numa oportunidade de desenvolver o diálogo, a confiança e a humildade" (LIMA e VAZ, 2019, p. 3). Fisher e Ury (2014), antropólogo americano, empresta sua contribuição para o debate corroborando a ideia de uma mediação eficaz que privilegie o bom senso, democratiza o acesso à justiça e dissemina a pacificação social, extratificada em um acordo finalmente celebrado entre os interessados, consoante Souza (2013, p. 207) preleciona.

Igual relevo denota-se nas Escolas clássicas Tradicional-Linear de Harvard, consolidada na mediação passiva, inadmitindo a intervenção direta do mediador que se limita a ser um facilitador entre os interessados adotando técnicas que contribuem para efetivar a autocomposição. Tem como condicionante, separar pessoas de problemas, com vistas a mitigar os ressentimentos, arrefecer as questões pessoais e manter o foco na solução do conflito, na celebração do acordo, que é seu objetivo central.

Por fim, no modelo Circular-Narrativo de Sara Cobb, que explica o poder da comunicação circular e se constrói sob as premissas da Teoria dos Sistemas de Luhmann, sublinha a preocupação com a circularidade e a interdependência das pessoas, pelo que insiste então compreender a outra parte, 
suas particularidades, interesses, objetivos e características. Com evidência na espécie "circular narrativa", a causalidade não é mais imediata, tal como no modelo de Harvard. Para que as partes compreendam uma a outra, mediante um processo de conversação facilitada por um terceiro estranho, é preciso analisar não a causa imediata que determina aquela situação problema, mas o conjunto de causas remotas, anteriores, que de alguma forma contribuíram para o deslinde conflitual (LUZ, 2015, p. 121).

Esse "conjunto de causas remotas" faz surgir a "lide sociológica", exigindo uma atenção especialmente redobrada. Fato é que ao resolvê-la, então a lide processual muitas vezes também desaparece, haja vista que nem sempre o processo traduz o real interesse do Demandante e nem do Demandado. É nesse sentido a seguinte ponderação:

Por outro lado, a descrição do conflito segundo os parâmetros preconizados pelos
próprios envolvidos denomina-se de lide sociológica. O novo CPC, em seu artigo
334 envida esforços para prestigiar a Resolução integral do conflito presumindo que
desta forma melhor se proporcionar à sociedade a pacificação efetiva. Não basta
resolver a lide processual - aquilo que foi trazido pelos advogados ao processo -
se os verdadeiros interesses que motivaram as partes a litigar não forem
identificados e resolvidos. Exemplificativamente, em determinada demanda julgada
em Minas Gerais (TJ-MG, AC $408.550-5,7^{a}$ Câmara Cível, publ. DJMG $\left.29 / 4 / 2004\right)$
na qual se deferiu pedido de danos morais a um filho por abandono afetivo de
seu pai, houve repercussão significativa após entrevista do autor a um
programa de televisão no qual este chorava ao afirmar que não conseguiu o que
queria - mesmo tendo lhe sido deferido o pedido. O autor, afirmou na
entrevista que, ao ficar sabendo da referida decisão, seu pai lhe informou que
nunca mais lhe dirigira a palavra. Ainda nesta entrevista o autor chorando
disse que "não era isso que queria". Constata-se que na lide processual houve
formalmente um vencedor (i.e. o filho) e um perdedor (i.e.o pai), todavia, na
realidade (ou na lide sociológica) ambos certamente saíram insatisfeitos do
processo de Resolução de disputa - neste conflito houve dois perdedores
(AZEVEDO; BUZZI, 2019 , grifo nosso).

Infere-se, portanto, que a lide não começa no processo judicial, mas este é apenas a superfície do lago, uma vez que em geral a demanda é a fotografia de um conjunto de sofrimentos emanados de relações sociais que se desgastam pela força do tempo e urgem ser restauradas. Sem essa sensibilidade o Poder Judiciário exaurirá suas forças, onerará o Estado e não logrará a paz e a justiça sonhadas pela medição e pela conciliação que então, lamentavelmente, restarão frustradas.

Impende assim salientar que na mediação e na conciliação o desejo primevo deve ser a identificação das emoções mutiladas e dos sentimentos encarcerados nos escombros das relações sociais que envolvem as pessoas protagonistas da ação judicial então colocada em pauta. Afinal, o desafio do Novo Código de Processo Civil, é resolver sobretudo o conflito, e 
não apena o processo, haja vista que os dramas que afligem a alma dos cidadãos não são respondíveis por regras meramente formais, técnicas e legalistas.

c) A (Des)valorização pelo Judiciário do(a) profissional mediador(a) e conciliador(a)

Com o real anseio de consolidar efetivamente a profissão de mediadores e conciliadores, o novo CPC reservou-lhes normas específicas, classificando-os como judiciais e extrajudiciais, consagrando um cadastro nacional para seu possível registro, impondo uma capacitação mínima prestada por órgão credenciado. Regulamenta, portanto, este novel ofício, inclusive estabelecendo um Código de Ética e dispondo acerca de concursos públicos e remuneração, admitindo também, nessa esteira, a hipótese da atividade ser desenvolvida de forma voluntária (art. 167 a 169 do CPC).

Esta matéria, vale dizer, foi precedida pelo artigo $7^{\circ}$, VII da Resolução no 125/2010 do CNJ, ao determinar que os Núcleos Permanentes de Métodos Consensuais de Solução de Conflitos (NUPEMECs), regulamentem "se for o caso, a remuneração de conciliadores e mediadores, nos termos da legislação específica" (CNJ, 2010).

Outrossim, saliente-se o preceituado no art. $8^{\circ}$ da Lei n.13.140/2015, que equipara os mediadores a servidores públicos para fins de responsabilidade criminal, a saber: " $O$ mediador e todos aqueles que o assessoram no procedimento de mediação, quando no exercício de suas funções ou em razão delas, são equiparados a servidor público, para os efeitos da legislação penal" (BRASIL, 2015b, p. 2).

Destarte, é que inobstante a imprescindibilidade desses profissionais para que a mediação e a conciliação judiciais alcancem efetivamente os seus elevados propósitos, o Estado não os tem remunerado até o presente momento, condicionando esse ofício ao trabalho voluntário.

Nesta esteira, em 28 de novembro de 2018, o CNJ apresentou proposta de profissionalização do mediador e do conciliador:

Entendemos que o conciliador deve ser bem capacitado e bem remunerado para que ele possa se profissionalizar. Não queremos um mediador que tenha essa atividade como um bico. Mas que possa cada vez mais se capacitar e prestar um bom serviço à sociedade. Anos atrás, a conciliação não tinha tanta importância como hoje. Atualmente, não é mais possível contarmos apenas com ajuda de estagiários ou voluntários", afirmou o presidente do Fonamec, Paulo César Alves das Neves, juiz da $5^{\text {a }}$ Vara Cível de Goiânia. [...] (CNJ, 2019b, p. 1). 
Insta salientar que essa não remuneração, associada à ausência de uma infraestrutura específica para o desenvolvimento dos trabalhos, dentre outras limitações do sistema, pode estar subtraindo parte importante do impacto positivo descomunal que a mediação deveria gerar na sociedade.

A Fadivale, pretendendo contribuir para a superação desses preocupantes desafios, tem fomentado relevantes projetos e promovido expressivas iniciativas, dentre as quais destacam-se:

a) Instituiu a matéria de Mediação na matriz curricular de sua graduação em direito quando o Ministério da Educação ainda não a havia tornado obrigatória nas Diretrizes Curriculares Nacionais - DCN's (MEC, 2018);

b) Realizou em 2017 um evento de alta envergadura sobre mediação em seu auditório, por intermédio da pós-graduação, com a presença dos ícones nacionais desta área, que promoveram palestras e atividades outras ricas atividades que envolveram toda a comunidade acadêmica;

c) Criou em 2017 a pós-graduação presencial em Mediação;

d) Estabeleceu convênio com a Fundação Nacional de Mediação de Conflitos FNMC, Câmara Privada de Mediação sob a direção da Dra. Fernanda Lima, que tem parceria com o CNJ e ofereceu para 45 pós-graduandos que concluíram o curso em novembro de 2018 a capacitação em mediação judicial e extrajudicial, inclusive com atendimentos à comunidade carente por ocasião das aulas práticas, com sessões realizadas nas dependências da Instituição nas sextas-feiras a noite e aos sábados, cujos acordos foram encaminhados para homologação ao Poder Judiciário;

e) a criação em 2018 de um Grupo de Pesquisa e Trabalho sobre 'Direitos Humanos, acesso à justiça e os meios extrajudiciais de solução de conflitos", que tem desenvolvido relevante produção científica em torno da temática, promovendo eventos, buscado estreitar vínculos com o CEJUSC local;

f) Encontra-se em via de negociações para instituir em suas próprias dependências um Posto de Atendimento Pré-Processual (PAPRE) para atendimento da comunidade que poderá buscar a solução de seus conflitos sem necessariamente acionar a via processual.

CONCLUSÃO 
Este trabalho objetivou investigar se a mediação e a conciliação, como meios de pacificação e inclusão social que auxiliam os indivíduos na busca da prevenção e solução dialogada dos conflitos, estão de fato se revelando potencialmente capazes de promover a democracia por meio do acesso à justiça, instrumentalizando as minorias com os seus direitos e garantias constitucionais.

Conclui-se que existe sim uma profícua união de forças da sociedade e do estado para a consecução deste improrrogável ideal que vem lentamente se materializando por meio de políticas públicas e privadas de fomento aos meios adequados de solução das controvérsias preconizadas mundialmente há algumas décadas.

No capítulo 4 deste artigo, afere-se que consoante informe "Justiça em Números" do Conselho Nacional de Justiça (CNJ), ano-base de 2017, demonstrou- que o Poder Judiciário finalizou aquele ano com 80,1 milhões de processos em tramitação, aguardando alguma solução definitiva.

A Faculdade de Direito do Vale o Rio Doce (Fadivale), por sua vez, vem se empenhando herculeamente como agência de pacificação social via mediação e conciliação, sonho este extratificado nas relevantes iniciativas descritas no capítulo 5, alínea c, consolidado a partir da pesquisa-ação. Sendo assim, ousa ser propositiva, com o fito de prosseguir nesse projeto emancipatório e cidadão, vislumbrando:

a) A conclusão do projeto, que já está avançado, para a instalação do Posto de Atendimento Pré-Processual- PAPRE nas dependências da Fadivale, vinculado ao setor de estágio e também à pesquisa e extensão e futuramente implementar uma unidade deste na periferia da cidade de Governador Valadares/MG, em conjuntos de bairros que poderão ser organizados por regiões, após serem mapeadas as suas principais demandas sociais, cíveis, penais etc;

b) A conclusão do projeto de instalação na Fadivale de um Polo Avançado de Formação de Mediadores e Conciliadores pelo TJMG, em parceria como CNJ, atualmente em fase de elaboração;

c) A otimização da mediação, da conciliação, da negociação, constelação (Direito Sistêmico) e demais formas adequadas de solução de controvérsias junto aos seus núcleos de estagio, com vistas a desenvolver habilidades e competências essencialmente pacificadoras nos acadêmicos para melhor cumprirem a sua função social; 
d) Fortalecimento do grupo de pesquisa e trabalho já existente na faculdade e por ela reconhecido, para o estudo dos "Direitos Humanos e o Acesso à Justiça pelos Meios Extrajudiciais de Solução de Conflitos-MESCs", o qual tem empreendido esforços para obter seu cadastro junto a fontes de fomento a exemplo do CNPQ.

Finalmente, com esse olhar de vanguarda, a Fadivale, ainda em clima de celebração de seu Cinquentenário festejado efusivamente ano passado, demonstra que está realmente empenhada em cumprir, por meio da conciliação e da mediação, sua tão nobre e sublime missão: "Oferecer um ensino jurídico de qualidade, em nível de graduação e pós-graduação, formando profissionais com a necessária competência para atuarem de forma ética e comprometida com as transformações exigidas pela sociedade”. (FADIVALE, 2015, p. 14).

\section{REFERÊNCIAS}

ARISTÓTELES. Ética a Nicômaco. Tradução de Mário da Goma Kury. Brasília: Editora da UnB, 1984.

AZEVEDO, André Gomma de (org.). Manual de mediação judicial. 7. ed. Grupos de Pesquisa: Brasília, DF: 2018.

AZEVEDO, André Gomma de, BUZZI, Marco Aurélio. Novos desafios para a mediação e a conciliação no novo CPC. Revista Consultor Jurídico, 11 de novembro de 2016. Disponível em: https://www.conjur.com.br/2016-nov-11/novos-desafios-mediacao-conciliacao-cpcartigo-334. Acesso em: 20 jul. 2019.

BEDIN, Gabriel de Lima. SPENGLER, Fabiana Marion. O direito de acesso à Justiça como concretização dos direitos humanos: garantias no Âmbito Nacional Internacional. In: SPENGLER, Fabiana Marion. BEDIN, Gilmar Antônio (org.) Acesso à justiça, direitos humanos \& Mediação (recurso eletrônico). Curitiba: multideia, 2013.

BARBOSA, Rui. Oração aos moços. São Paulo: Martin Claret. 2004. p. 53

BRASIL. Constituição da República Federativa do Brasil: promulgada em 5 de outubro de 1988: atualizada até a Emenda Constitucional n. ${ }^{\circ}$ 99, de 14.12.2017. Brasília, DF: Presidência da República, 1988. Disponível em:

http:www.planalto.gov.br/ccivil_03/constituicao/constituicao.htm. Acesso em: 28 jul. 2019a.

BRASIL. Lei n. 13.140, 26 de junho de 2015. Dispõe sobre a mediação entre particulares como meio de solução de controvérsias e sobre a autocomposição de conflitos no âmbito da administração pública; altera a Lei $n^{\circ} 9.469$, de 10 de julho de 1997 , e o Decreto $n^{\circ} 70.235$, de 6 de março de 1972; e revoga o $§ 2^{\circ}$ do art. $6^{\circ}$ da Lei $n^{\circ} 9.469$, de 10 de julho de 1997. Brasília, DF: Presidência da República, 2015. Disponível em: 
http://www.planalto.gov.br/ccivil_03/_ato2015-2018/2015/lei/113140.htm. Acesso em: 20 jul. 2019 b.

BRASIL. Lei no 13.105 de 16 de março de 2015. Código de processo civil. Brasília, DF: Presidência da República, 2015. Disponível em: http://www.planalto.gov.br/ccivil_03/_Ato2015-2018/2015/Lei/L13105.htm. Acesso em: 21 jul. 2019c.

BRASIL. Resolução n 125 de 19 de novembro 2010. Dispõe sobre a Política Judiciária Nacional de tratamento adequado dos conflitos de interesses no âmbito do Poder Judiciário e dá outras providências. Brasília, DF: CNJ, 2010.

BUSH, R. A. Baruch e FOLGER, Joseph P. La promesa de mediación: cómo afrontar el conflicto mediante la revalorización y el reconocimiento. Buenos Aires: Granica, 1996.

CAPPELlETTI, Mauro; GARTH, Bryant. Acesso à justiça. Tradução de Ellen Gracie Northfleet. Porto Alegre: Fabris, 1988.

CARNEIRO, Paulo Cezar Pinheiro. Acesso à justiça: juizados especiais cíveis e ação civil pública. Rio de Janeiro: Forense, 2000.

CAVALIERI FILHO, Sérgio. Programa de sociologia jurídica (você conhece?). 10. ed. Rio de Janeiro: Forense, 2003.

CITTADINO, Gisele. Pluralismo, direito e justiça distributiva. 3. ed. Rio de Janeiro: Lumen Juris, 2004. .

CNJ. Justiça em números 2018: ano-base 2017. Brasília, DF: Conselho Nacional de Justiça: 2018. Disponível em: http://www.cnj.jus.br/files/conteudo/arquivo/2018/08/44b7368ec6f888b383f6c3de40c32167.p df. Acesso em: 24 abr. 2019.

CNJ. CNJ decide esta semana sobre profissionalização de mediador e conciliador. Agência CNJ de Notícias. 28 novembro de 2018. Disponível em:

http:www.contabilidadenatv.com.br/2018/11/cnj-decide-esta-semana-sobreprofissionalizacao-de-mediador-e-conciliador. Acesso em: 20 jul. 2019.

CÓDIGO DE HAMURÁBI. Disponível em:

http://dhnet.org.br/direitos/deconu/textos/cese.htm. Acesso em: 20 jul.2019.

CÓDIGO DE MANU. Disponível em: http://dhnet.org.br/direitos/deconu/textos/cese.htm. Acesso em: 20 jul. 2019.

CORTEZ, Frederico. Um judiciário de R \$ 49,9 bilhões para 2019. Focus.jor. Ceará. 23 abril de 2019. Disponível em: https://www.focus.jor.br/um-judiciario-de-r-499-bilhoes-para-2019/. Acesso em: 22 jul. 2019. 
GUSTIN, Miracy B. S, DIAS, Maria Tereza Fonseca. (Re)pensando a pesquisa Jurídica. Belo Horizonte: 2015.

FADIVALE. Projeto pedagógico 2015. Governador Valadares: Faculdade da Direito do Vale do Rio Doce. Projeto Pedagógico, 2015. p. 14.

FISHER, Roger, URY, William. Como chegar ao Sim (Getting to yes). Tradução de Ricardo Vasques Vieira. 3. ed. Rio de Janeiro: Salomon Editores. 2014.

FULLIN, Carmem Sílvia. Acesso à justiça: a construção de um problema em mutação. In: SILVA, Felipe Gonçalves; RODRIGUEZ, José Rodrigo (org.). Manual de sociologia jurídica. São Paulo: Saraiva, 2013. p. 219-236.

HABERMAS, Jürgen. Teoria de la Accion Comunicativa. Tomo I. Madri: Taurus Ediciones, 1999.

LEI DAS XII TÁBUAS. Disponível em: http://dhnet.org.br/direitos/deconu/textos/cese.htm. Acesso em: 20 jul. 2019.

LIMA, Fernanda; VAZ, Vânia. Mediação: o caminho para a disseminação de uma cultura de paz. Disponível em:

https://aplicacao.mpmg.mp.br/xmlui/bitstream/handle/123456789/1104/4\%20R\%20Mediacao $\% 20$ o $\% 20$ caminho $\% 20-\% 20$ Fernanda $\% 20 \mathrm{e} \% 20$ vania.pdf?sequence=1. Acesso em: 25 jul. 2019.

LIMA, Fernanda. A prática da mediação construtivista. Belo Horizonte: New Hampton Press Ltda, 2017.

LUZ, Lhana Martins. Justiça restaurativa: a ascensão do intérprete e a nova racionalidade criminal. Empório do Direito: 2015.

MEC. Resolução n. 5, de 17 de dezembro de 2018. Institui as Diretrizes Curriculares Nacionais do Curso de Graduação em Direito e dá outras providências. Brasília, DF: Ministério da Educação, 2018.

MINAS GERAIS. Tribunal de Justiça. Conciliação, mediação e cidadania. Alternativa eficaz e humana na solução de conflitos entre cidadãos que buscam a justiça. Números de atendimento da conciliação e mediação. 5 abr. 2017. Disponível em:

http://www.tjmg.jus.br/portal-tjmg/acoes-e-programas/conciliacao-mediacao-ecidadania.htm\#.XSEC0ehKjIX . Acesso em: 6 jul. 2019.

MOREIRA, Sandra Mara Vale. Mediação e democracia: uma abordagem contemporânea da resolução de conflitos. Mestrado (Dissertação). Universidade de Fortaleza. Fundação Edson Queiroz: Fortaleza, 2007.

NUNES, E. A gramática política do Brasil: clientelismo e insulamento burocrático. Rio de Janeiro: Zahar, 1997. 
ONU. Declaração Universal dos Direitos Humanos. Adotada e proclamada pela Assembleia Geral das Nações Unidas (resolução 217 A III) em 10 de dezembro 1948. Nações Unidas Brasil, UNICRio. Disponível em:

https://www.ohchr.org/EN/UDHR/Pages/Language.aspx?LangID=por. Acesso em: 26 fev. 2019.

PLATÃO. A República. In: Os pensadores - Vida e Obra. São Paulo: Abril Cultural, 1996.

ROCHA, Leonel, LOIS, Cecília e MELEU, Marcelino. Cátedra Luis Alberto Warat. Disponível em: ttp:www.conpedi.org.br/publicacoes/c178h0tg/2y368zo8. Acesso em: 30 jul. 2019.

SILVA, P.V.; PEDONE, L. Formação de políticas de governo: o caso brasileiro. Revista Brasileira de Estudos Políticos, Belo Horizonte, n. 66, p. 203-220, 1988.

SIX, Jean François. Dinâmica da mediação (Dynamique de la médiation). Tradução de Giselle Groeninga de Almeida, Águida Arruda Barbosa e Eliana Riberti Nazareth.

Belo Horizonte: Del Rey, 2001.

SOUZA, Luciane Moessa de. Mediação de conflitos e o novo Código de Processo Civil. In: SPENGLER, Fabiana Marion. BEDIN, Gilmar Antônio(org.). Acesso à justiça, direitos humanos \& Mediação (recurso eletrônico). Curitiba: multideia, 2013.

URY, William. Supere o não: negociando com pessoas difíceis: como fechar grandes negócios transformando seu oponente em parceiro. 5. ed. Rio de Janeiro: Bestseller, 2008.

ZEHR, Howard. Justiça restaurativa (Restorative Justice). Tradução Tônia Van Acker. São Paulo: Palas Athena, 2012. 